\title{
Unsteady Magnetohydrodynamics oscillating flow of third order fluid with central free stream velocity
}

\author{
Nhdal.M.Abdal Ameer * $\quad$ Ahamad M. Abdal Hadi** \\ Received 18, September, 2011 \\ Accepted 9, April, 2012
}

\begin{abstract}
:
In this article the unsteady magnetohydrodynamics oscillating flow of third order fluid with free stream velocity is proposed. It is found that the motion equation is controlled by five dimensionless parameters namely the coecostic parameter $\beta_{4}$, viscoelostic parameter $\Phi$, acceleration/deceleration c,suction/blowing $\mathrm{d}$ and material constants $\alpha$. The effect of each of these parameters upon the velocity distribution is analysised.
\end{abstract}

Keywords: Unsteady flow, Magnetohydrodynamics(MHD), third order fluid, oscillating flow.

\section{Introduction:}

Fluid mechanics has fascinated many generations of scientists and engineers although many years of research have been devoted to the study of fluids of low molecular weight . The motion of any fluid is described by the equations of conservation of mass, momentum , and energy. physically, the equation of continuity states that within a small fixed volume there can be no net rate of addition mass .The equation of momentum describes that the mass time -acceleration of fluid element equals the sum of the pressure, viscous, and gravitational forces acting on the element, and the energy equation interprets that the temperature of a fluid element changes as it moves along with the fluid because of heat conduction and heat production by viscous heating [1 ,2 ]. In general, these three equations are used to describe the flow behavior but there are few situations under which the energy equation is not important for example,in sufficiently slow flows, viscous heating is not essential. In recent years, the flows of second order have been studied extensively and we refer to papers by Asghar. S, Hayat. Tand Siddiqui. A.M [3] which is studied moving boundary in a second-grade fluid .Which paper [4] discusses an increasing velocity amplitude of the oscillating porous plate it shows that in case of secondgrade fluid a combination of suction /injection and decreasing/increasing velocity amplitude is possible as well. Later Ramano Murth. Ch .V and Kavitha. K.R. [5] studied flow of a second order fluid over an inclined porous plate under the influence of applied Magnetic field.In the present work, we discuss the viscous of nonNewtonian problem of an unsteady MHD third order fluid flow past an infinite oscillating porous plate. This work is modified of Muhammad R. mohyuddin [6] which discusses oscillating flow of second order and studied the effect of suction, acceleration and MHD. He observed the boundary layer decrease and the velocity is increase in case of suction $(d=-2,-1)$ but in case $(d=0.5,1)$ the boundary layer becomes large, also it

\footnotetext{
Department of mathematics ,College of Science for Women, Baghdad University

**Department of mathematics, College of Science, Baghdad University
} 
observed with difference that MHD parameter $\alpha$ is increased to 0.5 .

\section{Formulation of the problem 1}

Let us assume that the $\mathrm{x}$-axis is parallel to the oscillating porous plate and the $y$-axis is perpendicular to it, also we will assume that the third order fluid initially at rest thus the velocity field is given by

$$
\vec{V}=\left[u(y, t), v_{0}, 0\right]
$$

and $\mathrm{v}_{0}>0$ are Where $\mathrm{u}(\mathrm{y}, \mathrm{t})$ is the velocity in the $\mathrm{x}$-direction, $\mathrm{v}_{0}<0$

correspondent to suction and blowing velocities respectively. For $t>0$ plate is

moved period according to $\mathrm{u}(0, \mathrm{t})=\mathrm{u}(\mathrm{t})=\mathrm{u}_{0} \mathrm{e}^{(\beta-\mathrm{i} \omega) \mathrm{t}}($

$\omega>0, \mathrm{t}>0, \beta=$ constant $\neq 0$ )

In this case the continuity and motion equations are

$$
\begin{aligned}
& \overrightarrow{\mathrm{div}}=0 \\
& \rho\left(\frac{\partial \overrightarrow{\mathrm{v}}}{\partial \mathrm{t}}\right)=\overrightarrow{\mathrm{p}}+\operatorname{div} \mathrm{T}+\overrightarrow{\mathrm{J}} \times \vec{\beta} \\
& \overrightarrow{\mathrm{J}} \times \vec{\beta}=-\sigma \beta_{0}^{2} \mathrm{u}
\end{aligned}
$$

Where $\vec{j}$ is the electric current density, $\vec{\beta}$ is the magnatic field, $\sigma$ is the electrical conductivity of the fluid and the stress tensor $\mathrm{T}$ is defind by

$$
\mathrm{T}=-\mathrm{PI}+\mu \mathrm{A}_{1}+\alpha_{1} \mathrm{~A}_{2}+\alpha_{2} \mathrm{~A}_{1}^{2}+\beta_{3}
$$

$\left(\operatorname{tr} \mathrm{A}_{1}\right) \mathrm{A}_{1}$

Where $\mathrm{P}$ is the pressure, $\mu$ is the dynamic viscosity, $\mathrm{I}$ is the identity tensor , $\alpha_{i}(i=1,2)$ and $\beta_{3}$ are the material constants[7]. The RivlinEricksen tensors are

$$
\begin{aligned}
& A_{1}=\nabla \vec{V}+(\nabla \vec{V})^{\prime} \\
& A_{2}=\frac{\partial A_{1}}{\partial t}+(\vec{V} \cdot \nabla) A_{1}+A_{1} \nabla \vec{V}+(\nabla \vec{V})^{\prime} A_{1}
\end{aligned}
$$

In which the prime sign represent the transpose of matrix and $\nabla$ is the gradient operater.In addition to that we will assume $v=$ constant $=v_{0}$ and the follow

constraints

are

imposed $\mu \geq 0$,

$\alpha_{1} \geq 0,\left|\alpha_{1}+\alpha_{2}\right| \leq \sqrt{2 \mathrm{u} \mu \beta_{3}}, \beta_{3} \geq 0$.
Now, by using equations (3), (4) and (5) the motion equation (2) reduces to

$$
\begin{aligned}
& \left(\frac{\partial^{2} \mathrm{u}}{\partial y \partial \mathrm{t}}+v_{0} \frac{\partial^{2} \mathrm{u}}{\partial y^{2}}\right)=v \frac{\partial^{\mathrm{s}} \mathrm{u}}{\partial y^{\mathrm{a}}}+ \\
& \frac{a_{1}}{\rho} \frac{\partial^{4} \mathrm{u}}{\partial \mathrm{t} \partial \mathrm{y}^{\mathrm{a}}}+\frac{6 \beta_{\mathrm{g}}}{\rho} \frac{\partial}{\partial \mathrm{y}}\left(\frac{\partial \mathrm{u}}{\partial \mathrm{y}}\right)^{2} \frac{\partial^{2} \mathrm{u}}{\partial y^{2}}-\frac{\sigma \beta_{0}^{2}}{\rho} \frac{\partial u}{\partial y}
\end{aligned}
$$

Which corresponds to the following conditions $\mathrm{u}(0, \mathrm{t})=\mathrm{u}_{0} e^{(\beta-i \omega) t}, \mathrm{u}(\mathrm{y}, 0)=\mathrm{u}_{0}$ Integrating equation (6) with respect to $\mathrm{y}$, we get

$$
\begin{aligned}
& \left(\frac{\partial u}{\partial t}+v_{0} \frac{\partial u}{\partial y}\right)=v \frac{\partial^{x} u}{\partial y^{2}}+ \\
& \frac{\alpha_{1}}{p} \frac{\partial^{\mathrm{s}} u}{\partial t \partial y^{2}}+\frac{6 \beta_{s}}{p}\left(\frac{\partial u}{\partial y}\right)^{2} \frac{\partial^{2} u}{\partial y^{2}}-n u+k(t) \ldots(7)
\end{aligned}
$$

Where $\mathrm{n}=\frac{\sigma \beta_{0}^{\mathrm{z}}}{\rho}, \mathrm{v}=\frac{\mu}{\rho}$ and $\mathrm{k}(\mathrm{t})$ is the integration constant

If we assume that $u(y, t) \rightarrow f_{1}(t)$ as $y \rightarrow \infty$, then from (7) wehave

$$
\mathrm{k}(\mathrm{t})=\frac{\partial \mathrm{f}_{1}}{\partial \mathrm{t}}+\mathrm{nf}_{1}(\mathrm{t})
$$

Equation (7) can be written as

$$
\begin{aligned}
& \frac{\partial u}{\partial t}+v_{0} \frac{\partial u}{\partial y}-v \frac{\partial^{\mathrm{z} u}}{\partial y^{2}}-\frac{\alpha_{1}}{\rho} \frac{\partial^{\mathrm{s} u}}{\partial \mathrm{t} \partial \mathrm{y}^{2}}-6 \frac{\beta_{\mathrm{g}}}{\rho} \\
& \left(\frac{\partial \mathrm{u}}{\partial \mathrm{y}}\right)^{2} \frac{\partial^{\mathrm{z}} \mathrm{u}}{\partial \mathrm{y}^{2}}+\mathrm{nu}=\frac{\partial \mathrm{f}_{1}}{\partial \mathrm{t}}+\mathrm{nf}_{1}(\mathrm{t})
\end{aligned}
$$

where $f_{1}$ is the free stream velocity and will be solved subject to the boundary and initial conditions

$$
\begin{array}{ll}
\mathrm{u}(0, \mathrm{t})=\mathrm{u}(\mathrm{t})=\mathrm{u}_{0} \mathrm{e}^{(\beta-\mathrm{i} \omega) \mathrm{t}}{ }_{,} & \mathrm{u}(\infty, \mathrm{t}) \quad=\mathrm{f}_{1 s} \\
\mathrm{u}(\mathrm{y}, 0)=\mathrm{u}_{0} & . .(9)
\end{array}
$$

To give some physical meaning for the problem we assume that $\mathrm{f}_{1}=\mathrm{u}_{0}=$ constant , then equation (8) reduce to $\frac{\partial \mathrm{u}}{\partial \mathrm{t}}+v_{0} \frac{\partial \mathrm{u}}{\partial \mathrm{y}}-\mathrm{v} \frac{\partial^{\mathrm{z}} \mathrm{u}}{\partial \mathrm{y}^{2}}-\frac{\alpha_{1}}{\rho} \frac{\partial^{\mathrm{u}} \mathrm{u}}{\partial \mathrm{t} \partial \mathrm{y}^{2}}-6 \frac{\beta_{\mathrm{g}}}{\rho}$ $\left(\frac{\partial u}{\partial y}\right)^{2} \frac{\partial^{2} u}{\partial y^{2}}=\left(u_{0}-u\right) n$

Which may be written as $\frac{\partial \mathrm{f}}{\partial \tau}+$

$\sqrt{2} \mathrm{~d} \frac{\partial \mathrm{f}}{\partial \eta}-\frac{1}{2} \frac{\partial^{\mathrm{p} f}}{\partial \eta^{2}}-\Phi \frac{\partial^{\mathrm{s}} \mathrm{f}}{\partial \tau \partial \eta^{2}}-\beta_{4}\left(\frac{\partial \mathrm{f}}{\partial \eta}\right)^{2}\left(\frac{\partial^{\mathrm{p}} \mathrm{f}}{\partial \eta^{2}}\right)$ $=\alpha(1-f)$

Where $\eta=$
$\sqrt{\frac{\omega}{2 v}} y_{,} c=\frac{\beta}{\omega}, d=\frac{v_{0}}{2 \sqrt{\omega \omega}}, \tau=\omega t, f=\frac{u}{u_{0}}, \Phi$ 
$=\frac{\omega}{2 \mathrm{u}} \beta\left(\beta=\frac{\alpha_{1}}{\rho}\right), \beta_{4}=\frac{6 \beta_{8}}{4 \rho v^{2}} \mathrm{u}_{0}{ }^{3} \omega^{2}$

,$\alpha=\frac{\sigma \beta_{0}{ }^{2}}{\rho \omega}$ and the boundary conditions are $\quad f(0, \tau)=f(\tau)=e^{(c-i) \tau}, f($ $\infty, \tau)=1, f(\eta, 0)=1$

Equation (11) is a nonlinear partial differential equation of third order and its solution is given in the next section.

Solution of the problem

Let $g=1-f$ then the equation (11) reduces to

$\frac{-\partial \mathrm{g}}{\partial \tau}-\sqrt{2} \mathrm{~d} \frac{\partial \mathrm{g}}{\partial \eta}+$

$\frac{1}{2} \frac{\partial^{2} g}{\partial \eta^{2}}-\Phi \frac{\partial^{\mathrm{g}} \mathrm{g}}{\partial \tau \partial \eta^{2}}-\beta_{4}$

$\left(\frac{\partial g}{\partial \eta}\right)^{2}\left(\frac{\partial^{2} g}{\partial \eta^{2}}\right)=\alpha g$

and the boundary conditions become

$\mathrm{g}(0, \tau)=1-$

$e^{(c-i) \tau}, g(0, \tau)=0$

To solve equation (12) we expand $g$ in terms of $\beta_{4}$ and as follows

$$
\mathrm{g}=\mathrm{g}_{1}+\beta_{4} \mathrm{~b} \text { ? }
$$

Note that,we use this expansion to cover the results obtained by[4], where $\mathrm{g}_{1}$ is corresponding to his solution [eq. (9), $\frac{\partial^{x_{u}}}{\partial y \partial t}+$

$\left.v_{0} \frac{\partial^{2} \mathrm{u}}{\partial y^{2}}-v \frac{\partial^{\mathrm{s}} \mathrm{u}}{\partial y^{2}}+\mathrm{n} \frac{\partial \mathrm{u}}{\partial \mathrm{y}}=0\right]$.

Putting the last expression into equation (12), we obtain the following two equations:

$$
-\frac{\partial \mathrm{g}_{1}}{\partial \tau}-\sqrt{2} \mathrm{~d} \frac{\partial_{\mathrm{B}_{1}}}{\partial \eta}+\frac{1 \partial^{\mathrm{n}} \mathrm{g}_{1}}{2 \eta^{2}}+\Phi \frac{\partial^{\mathrm{g}} \mathrm{g}_{1}}{\partial \tau \partial^{2} \eta^{2}}=\alpha \mathrm{g}_{1}
$$

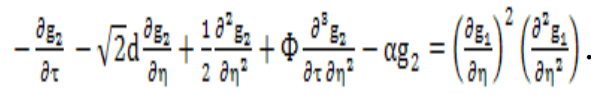

To solve equation (15), substitute $\mathrm{g}_{1}(\eta, \tau)=\mathrm{h}_{1}(\eta) \mathrm{e}^{(\mathrm{c}-\mathrm{i}) \tau}$ into(15) we get an ordinary differentional equation of the second order,which is

$$
\begin{aligned}
& \left(\Phi(c-i)+\frac{1}{2}\right) \frac{\partial^{2} h_{1}}{\partial \eta^{2}} \\
& -\sqrt{2} d \frac{\partial h_{1}}{\partial \eta}=(\alpha+(c-i)) h_{1}(\eta)
\end{aligned}
$$

Similarly, to solve equation (16), let $\mathrm{g}_{2}(\eta, \tau)=\mathrm{h}_{2}(\eta) \mathrm{e}^{3(\mathrm{c}-\mathrm{i}) \tau}$ and

substitute this expression into equation (16), we obtain

$$
\begin{aligned}
& \left(3 \Phi(\mathrm{c}-\mathrm{i})+\frac{1}{2}\right) \frac{\partial^{2} \mathrm{~h}_{2}}{\partial \eta^{2}}-\quad \sqrt{2} \mathrm{~d} \frac{\partial \mathrm{h}_{2}}{\partial \eta}- \\
& (3(\mathrm{c}-\mathrm{i})+\alpha) \mathrm{h}_{2}=\left(\frac{\partial \mathrm{h}_{1}}{\partial \eta}\right)^{2} \frac{\partial^{2} \mathrm{~h}_{1}}{\partial \eta^{2}} \quad \ldots(18)
\end{aligned}
$$

By solving equations(17) and (18), it is found that

$$
\begin{aligned}
& \mathrm{g}=- \\
& \mathrm{e}^{0.5\left(a-\sqrt{a^{2}+4 b}\right) n}\left(-1+\mathrm{e}^{(-i+c) \tau}\right)+\beta_{4}(2 \\
& \text { (- } \\
& a^{4}-4 a^{2} b-2 b^{2}+a^{3} \sqrt{a^{2}+4 b}+2 a b \\
& \left.\sqrt{a^{2}+4 b}\right) * \\
& e^{-\left(-3 a+3 \sqrt{a^{2}+4 b}+r\right) n}\left(-1+e^{(-i t c) r}\right)^{3} *\left(e^{0.5\left(-3 a+3 \sqrt{a^{2}+4 b}+2 r\right) n}\right. \\
& \left.\left.\mathrm{e}^{0.5\left(-6 a+6 \sqrt{a^{2}+4 b}+3 r-\sqrt{-4 q+r^{2}}\right) \eta}\right)\right) /(18 \\
& a^{2}+36 b+4 q+6 \sqrt{a^{2}+4 b r-} \\
& \left.6 a\left(3 \sqrt{a^{2}+4 b}+r\right)\right)
\end{aligned}
$$

Finally, by substituting $\mathrm{f}=1$-g in the last equation we found that $\mathrm{f}=1-(-$

$\mathrm{e}^{0.5\left(\mathrm{a}-\sqrt{\mathrm{a}^{2}+4 b}\right) \mathrm{n}}\left(-1+\mathrm{e}^{(-\mathrm{i}+\mathrm{c}) \tau}\right)+\beta_{4}($

2(-

$a^{4}-4 a^{2} b-2 b^{2}+a^{3} \sqrt{a^{2}+4 b}+2 a b \sqrt{a^{2}+4 b}$

*

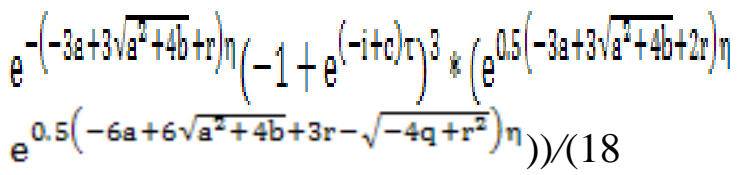

$a^{2}+36 b+4 q+6 \sqrt{a^{2}+4 b r}-$

$\left.6 a\left(3 \sqrt{a^{2}+4 b}+r\right)\right)$

Where

$\mathrm{a}=\mathrm{d} \sqrt{2} /\left(\Phi^{*}(\mathrm{c}-\mathrm{i})+0.5\right) ; \mathrm{b}=\alpha+\mathrm{c}-\mathrm{i}$;

$\mathrm{r}=\mathrm{d} \sqrt{2} /\left(\Phi^{*}(\mathrm{c}-\mathrm{i})+0.5\right)$;

$\mathrm{q}=(\alpha+\mathrm{i}-\mathrm{c}) /(\Phi *(\mathrm{c}-\mathrm{i})+0.5)$;

\section{Results and Discussion :}

In this section we study the effect of each parameter upon the velocity distribution to do this ,all figures are plots for non -dimensional velocity $\mathrm{f}$ against the non-dimensional variable $\eta$. The solution for velocity component $\mathrm{f}$ is plotted in all figures for different values of $\Phi, \beta_{4}, \alpha, \mathrm{d}, \mathrm{c}$ and for fixed time $\mathrm{pi} / 4$ as a function of the suction. The values of $\Phi, \beta_{4}, \mathrm{~d}, \mathrm{c}, \alpha$ are respectively

$\begin{array}{ll}\Phi=[0.01,0.07,1,2], & \beta_{4} \\ =[0.01,0.03,0.05,0.07], \quad \mathrm{d}=[-2,- & 1,-\end{array}$ 
$0.5,0], \mathrm{c}=[0,0.2,0.3,0.5] \quad$ and $\alpha$ is constant $(\alpha=0.1)$

\section{Effect $\beta_{4}$ on velocity}

Figs (1 ) illustrate the effect of coecostic parameter $\beta_{4}$ upon the velocity . In case o f $\mathrm{c}=0$ (acceleration) and the blowing parameter $\mathrm{d}=-0.5$,we note that as $\beta_{4}$ increase, the velocity decrease . Fig (2) shows the effect of $\beta_{4}$ where $\mathrm{c}=-0.5$ (deceleration) and $\mathrm{d}=0$ as the same as effect in fig (1) .

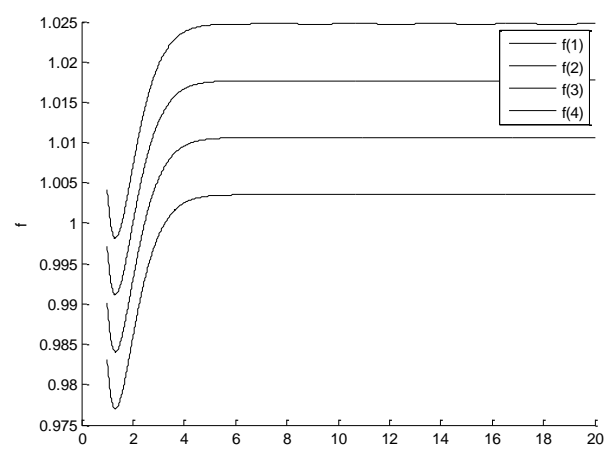

$\eta$

Fig(1)distribution velocity for $\beta_{4}=$ [ $0.01,0.03,0.05,0.07], \mathrm{d}=-0.5, \mathrm{c}=0, \alpha$ $=0.1, \quad \Phi=0 ; \tau=\mathrm{pi} / 4$

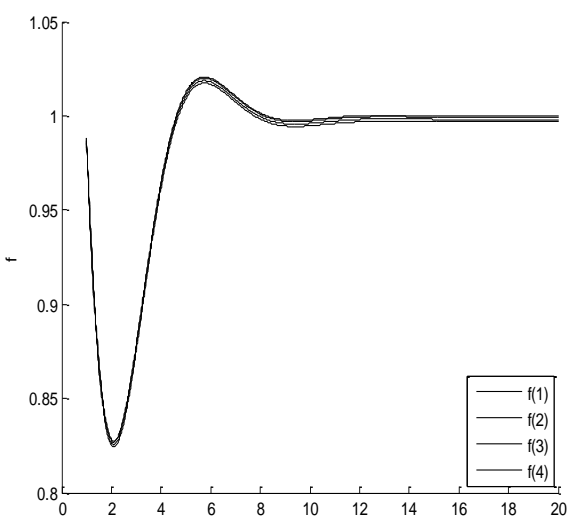

$\eta$

Fig(2)distribution velocity for $\beta_{4}=[$ $0.01,0.03,0.05,0.07], \mathrm{d}=0, \mathrm{c}=-0.5, \alpha$ $=0.1, \Phi=0, \tau=\mathrm{pi} / 4$

\section{Effect $\Phi$ on velocity}

Figs $(3,4)$ illustrate the effect of viscoelostic parameter $\Phi$ upon the velocity, its noted that with increase in $\Phi$ the velocity decrease. In fig(3) where $c=-0.5, d=0$ its observed that with increase of $\Phi$ from 0.01 to 0.07 the velocity increase, when $0.07<\Phi \leq 1$ the velocity increase .For $\Phi>1$ the velocity start to decrease. Fig (4 )also shows the similar results in fig(3) .

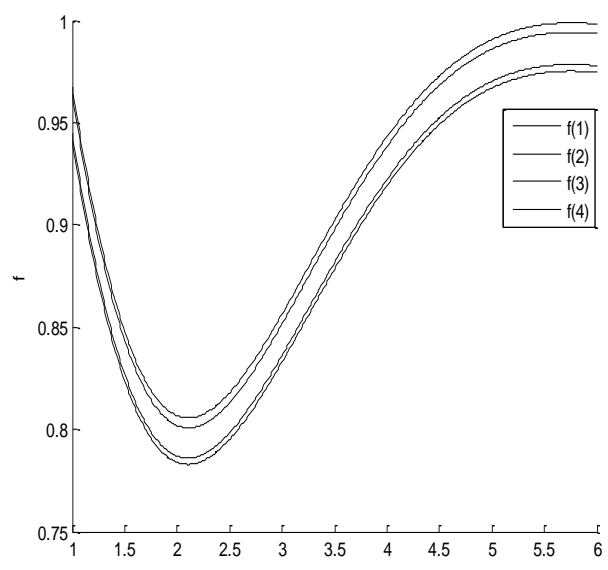

$\eta$

Fig(3 )distribution velocity for $[0.01,0.07,1,2], \mathrm{c}=-$ $0.5, \mathrm{~d}=0, \alpha=0.1, \beta_{4}=0.7, \tau=\mathrm{pi} / 4 \Phi=$

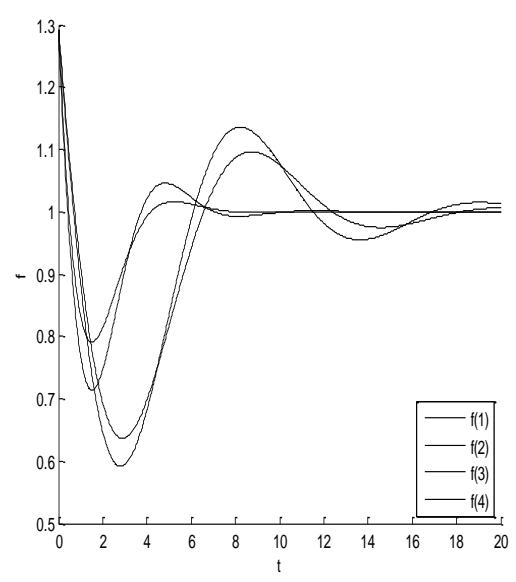

$\eta$

Fig( 4 )distribution velocity for $[0.01,0.07,1,2], \mathrm{c}=0, \mathrm{~d}=0.5, \alpha=0.1, \beta_{4}=0$ , $\tau=\mathrm{pi} / 4$

\section{Effect $c$ and $d$ on velocity}

Fig (5) shows that as $\mathrm{c}=-0.5, \beta_{4}=0, \Phi$ $=0.7$ the velocity decrease when increase of $d$. In fig (6) also the similar results in fig(5)with difference the velocity range decrease from 4.5 to1. Figs $(7,8)$ show the effect $\mathrm{c}$ on 
velocity, it observed that as c increase the velocity decrease

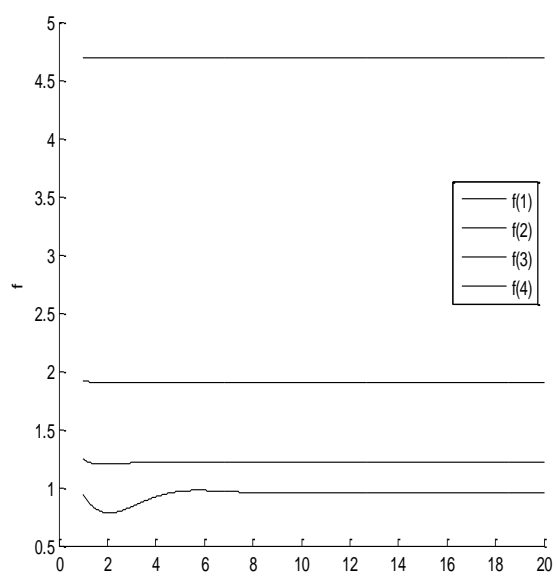

$\eta$

$\operatorname{Fig}(5)$ distribution velocity for $\mathrm{d}=[-2,-$ $0.5,-1,0], \mathrm{c}=-0.5 ; \beta_{4}=0.7, \alpha=0.1, \Phi=$ $0, \tau=\mathrm{pi} / 4$

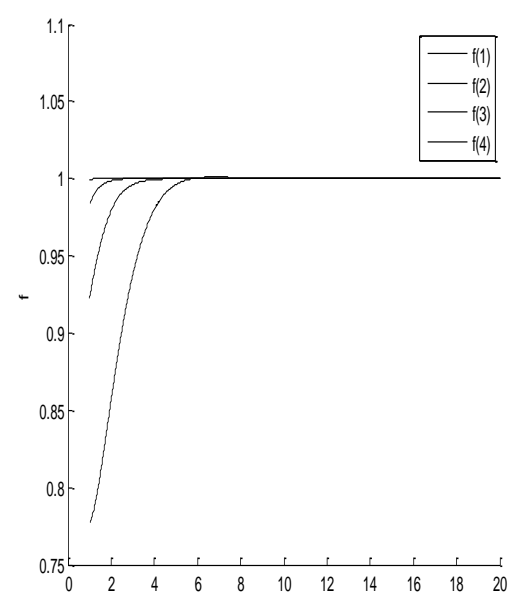

$\eta$

Fig( 6)distribution velocity for $\mathrm{d}=[-2,-$ $0.5,-1,0], \mathrm{c}=0.5 ; \beta_{4}=0, a=0.1, \Phi=0$ ,$\tau=\mathrm{pi} / 4$

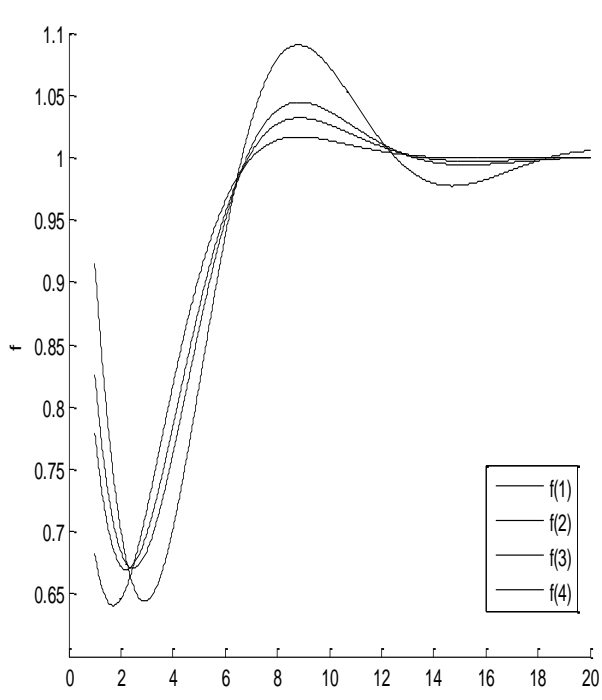

$\eta$

Fig ( 7)distribution velocity for $\mathrm{c}=[0$ $, 0.2,0.3,0.5], \mathrm{d}=0.5, \beta_{4}=0, \alpha=0.1, \Phi=0$ , $\tau=\mathrm{pi} / 4$

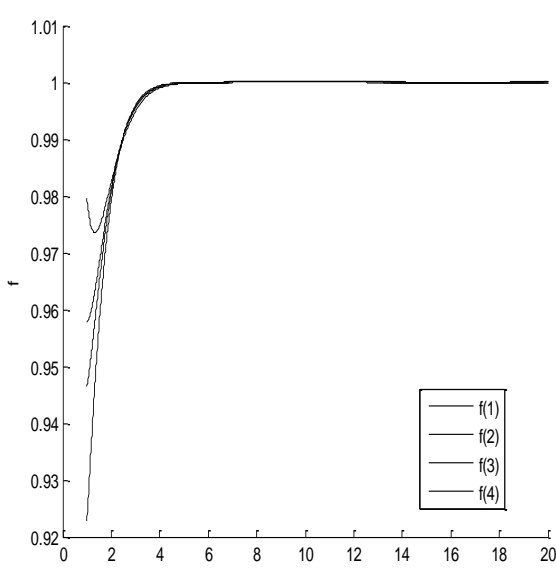

$\eta$

Fig( 8)distribution velocity for $\mathrm{c}=[0$ $, 0.2,0.3,0.5], \mathrm{d}=-0.5, \beta_{4}=0, \alpha=0.1, \Phi=0$ , $\tau=\mathrm{pi} / 4$

\section{References:}

1. Batchelor G.K. 1967.An introduction to fluid dynamics. Cambridge university press, Cambridge, $2 \mathrm{~d}$ ed: 615.

2. Landau. L and Lifshitz E.M.1959. Fluid mechanics . Addison-Wesley ,Reading,MA,1st ed: 539. 
3. Asghar.S,T.Hayat. $\mathrm{T}$ and Siddiqui. A.M.2002.Moving boundary in anonNewtonian fluid ,Int. J. of Non-linear Mech. 37 :75-80.

4. Chung Liu. I.2005. Unsteady unidirectional MHD flows of anonNewtonion fluid saturated in aporous medium ,J. of the Chinese inst. of engs. 28(4) : 569-578 .

5. Romano Murth Ch .V., Kavitha K.R .2010. Flow of a second order fluid over an inclined porous plate under the influence of applied Magnetic field ,Ad. in theo. and appl. Math. 5(2) : 133-147.
6. Muhammad R.Mohyuddin . 2006. Unsteady MHD oscillating flow with general free stream velocity ,J. prime res. in Math . $2: 131-140$.

7. Hayat. T, Mohyuddin.M.R, Asghar.S and Siddiqui .A.M .2004. The flow of aviscoelastic fluid on an oscillating plate ,Zamm.Z.Angew .Mech.84(1) : 65-70.

$$
\begin{aligned}
& \text { الجريان المتذبذ ب اللا مستقر في حقل مغتاطيسي لمائع من الرتبة الثالثة ذو } \\
& \text { احمد مولودعبد/الهادي ** } \\
& \text { *ضال محسن عبدالأمبر }
\end{aligned}
$$

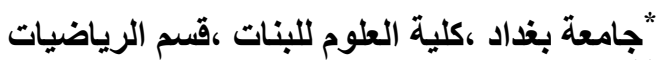

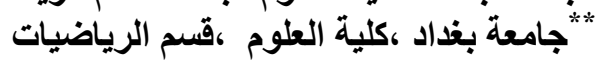

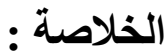

$$
\begin{aligned}
& \text { في هذا البحث تمت دراسة الجريان المتذبذ ب اللا مستقر في حقل مغناطيسي لمائع من الرتبة الثالثة ذو سرعة }
\end{aligned}
$$

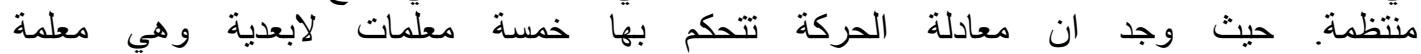

$$
\begin{aligned}
& \text {,acceleration/deceleration c,suction/blowing d , coecosticparameter } \beta_{4} \text {, viscoelostic } \\
& \text { وقد تم تحليل تأثير كل من هذه المعلمات على توزيع السرعة. parameter( ( ) }
\end{aligned}
$$

